\title{
AUTOMATIC GENERATION OF PLANAR RC STRUT-AND-TIE MODELS*
}

UDC 624.04:519.673:624.072.22=111

\author{
Anka Starčev-Ćurčin , Andrija Rašeta, Zoran Brujić \\ University of Novi Sad, Faculty of Technical Sciences, Serbia \\ \#astarcev@uns.ac.rs
}

\begin{abstract}
This paper presents a proposal for determining Strut-and-Tie models of reinforced concrete plane elements. For the purposes of analysis, a computer program was developed and a discrete topological optimization was applied, using a truss member for the design of the stress-strain state of the real member. The method can be used for the analysis of a part or a whole member and it is particularly suitable for the usage in the places of sudden changes of static and/or geometric characteristics of members. The general principle of the method is that compressed members replace concrete parts of the element (surface or volume) and tension members replace the reinforcement.
\end{abstract}

Key words: FEM, optimization, Strut-and-Tie model, truss member.

\section{INTRODUCTION}

Back in the nineteenth century, the idea of replacing the real structure with the equivalent truss one was introduced by the pioneers of research in this direction, namely Hennebique, Ritter and Mörsch. Many researchers were complementing and correcting each other in the manner of understanding and applying the method of compressed and tied members (Strutand-Tie Method), as a design method for a part or a whole member. The turn of the 21st century marked the introduction of the method in the codes of American (Canadian Standards Associations (CSA) and AASHTO LRDF Bridge Design Specifications, year 1994 [2], ACI 318-02, year 2002 [1]) and European continents (CEB-FIP Model Code, year 1990, EN 1992 [6]), and now finds its application almost all over the world.

Strut-and-Tie is a method utilizing a system of simple compressed and tied members to form the equivalent truss approximating the physical system, Figure 1.

Received December 5, 2012

* Acknowledgements: The work has been done within the scientific research project TR 36043 "Development and application of a comprehensive approach to the design of new and safety assessment of the existing structures for seismic risk reduction in Serbia", which is funded by the Ministry of Science of Serbia. 


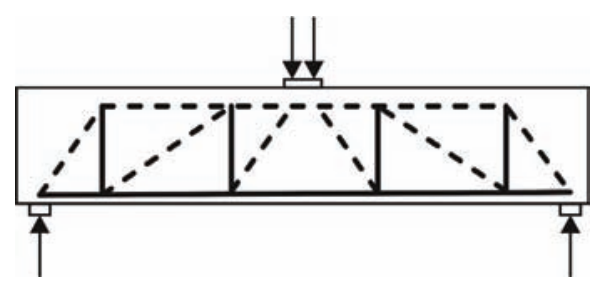

Fig. 1 The equivalent truss as the physical system

Compressed members replace concrete parts of the element (surface or volume) and tension members replace the reinforcement, which is the general principle of the method. In the truss model, the layout of members utilizes, in principle, the distribution of stress and principal stress trajectories corresponding to the results of the theory of elasticity with an idea to achieve the closest stress state in the reinforced concrete element. However, the behaviour of reinforced concrete cannot be sufficiently presented only by the theory of elasticity, since it is largely determined by the configuration of load and the arrangement of reinforcement, in terms of the layout and orientation of reinforcing bars. This provides an additional limiting conditions to the equivalent model of a reinforced concrete structure, opens the problem of modelling ambiguity, and can limit the application process for complex models; hence, that concrete solutions are still the result of engineering considerations based on experience and anticipated solutions.

The designed structure requires the fulfilment of the conditions of strength and usability. In the loaded structure, the static and deformation values are determined by the theory of structures and they are served for dimensioning the structure elements and for determining the required amount of reinforcement in the section or the dimensions of the section.

Technical flexural theory covers the design of reinforced concrete elements in the cases where all static values along the axis of the element are changing gradually, in the so-called B-regions, named after the English word beam or after the Bernoulli hypothesis on the linear distribution of strains in the section. In the cases of discontinuity (supports, joins, etc.), due to sudden changes of static forces or the geometry of structure, in the socalled D-region, named after the English words discontinuity and disturbed, the possibility of applying the usual manner of design is terminated, Figure 2.

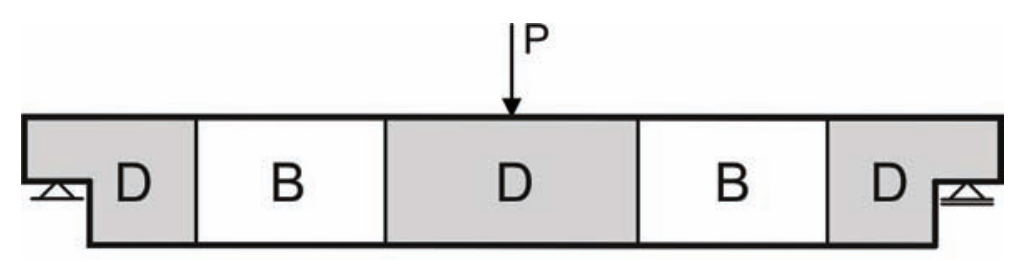

Fig. $2 \mathrm{~B}$ and D regions in the member

The boundaries between B and D regions are determined using St. Venant's rule under which the local disturbance of the stress field from the action of concentrated forces, closeness to a support or abrupt changes in geometry is lost at a distance approximately equal to the height of the element. A common structural detailing in the D-regions is based on the engineering experience and the experimental set recommendations. Their 
exact design confirmation is missing, and the absence of such a manner contributes to poorly designed and executed constructive details that affect the quality of the entire structure and lead to its damage and defects. There is a need for D-region design to be analysed, using the simple and rational models, and one of them is the Strut-and-Tie method that provides an insight into the real behaviour of reinforced concrete elements, the whole entity or its part.

\section{OPTIONS FOR MEMBER OPTIMIZATION}

For simpler and faster understanding of the stress-strain states of the structure or its parts, the discrete optimization can be applied, involving the modelling of the member according to its topology. The member becomes discrete in an appropriate manner by being reduced to a complex truss system that is obtained by connecting all points of the member with simple line elements. An example of a discrete topological optimization of the RC member is shown in Figure 3 a).

a)

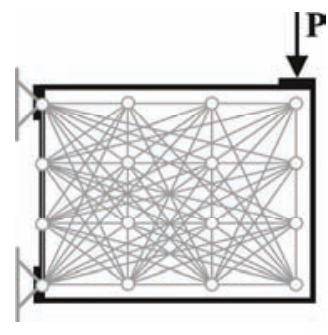

b)

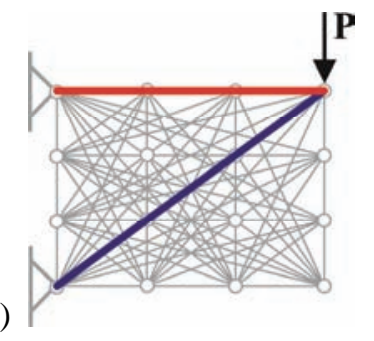

Fig. 3 a) Discrete topological optimization of the RC member;

b) Optimal form of the member

The determination of the optimum shape of the RC structure means that, for a given external action, it adopts the minimum amount of reinforcement required to achieve a sufficient capacity. This can be achieved from the initial system configuration by removing the less loaded elements i.e. simple members (Figure 3b). The system element ejection criteria can be made on the basis of various parameters such as stress, displacement, stiffness, system strain energy, etc.

The rigidity of certain elements of the system can be reduced to the desired manner of the layout of the reinforcement in the member [8], [9], and it can be determined following the expression:

$$
K_{i, j}=\beta_{i} \frac{E_{d} N_{i, j-1}}{L_{i} f_{d}}
$$

where $N_{i, j-1}$ is the force in the $\mathrm{i}^{\text {th }}$ simple member from the j-1 iteration, $E_{d}$ is the modulus of elasticity (pressure for concrete; tension for steel), $f_{d}$ is the design strength (pressure for concrete; tension for steel), $L_{i}$ is the length of a simple member and $\beta_{i}$ is the reduction coefficient of the reinforcement position in the member. According to the removing parameters, the limits not to be crossed are set as an optimal solution for the member. 
The method Evolutionary Structural Optimization (ESO) also represents a form of topological optimization, which involves a gradual removal of redundant parts of the material, and the load transfer takes place through the remaining parts of the structure. Separation criterion of parts of the material from the structure is done according to Von Mises's stress, which is a condition that none of the principal stresses do not reach the yield strength, but rather their combination. The stress state of each finite element is determined by comparing the Von Mises's stress in finite elements with the maximum von Mises's stress of the entire structure. At the end of each iteration in the analysis of finite element stress state, all elements that satisfy the expression (2), are removed from the model [4].

$$
\sigma_{v M}^{e} \leq R R_{i} \sigma_{v m, \max }
$$

where $\sigma_{v M}^{e}$ is Von Mises's stress in the finite element, $R R_{i}$ is the current rejection ratio and $\sigma_{v \max }$ is the maximum Von Mises's stress of the entire structure.

The analysis of the stress state and the removal of finite elements is repeated using the same values $R R_{i}$ in each iteration until it reaches a stable state, which means that in the iteration there is no more elements to be removed. Then the optimization process continues by adding an evolutionary rate $E R$ to the rejection ratio $R R_{i}(3)$.

$$
R R_{i+1}=R R_{i}+E R
$$

The value of the rejection ratio $\left(R R_{i}\right)$ and of the evolutionary rate $(E R)$ are initialized, for example, with $1 \%$. If in one or a small number of iterations too much finite elements are removed from the structure, the previously suggested value for RRi and ER must be reduced. With increasing the degree of the rejection ratio, the analysis of the stress state and a new finite element removal repeats in several iterations, until it again reaches a stable state. The process of the optimization by stresses continues until reaching the desired optimum, which can be, for example, a reason to obtain a certain shape and arrangement of finite elements to achieve the design model in the Strut-and-Tie method for dimensioning the whole structure or its parts. It would be ideal to get a full used stress model, but it is possible only in few cases [4].

In contrast to the discrete optimization of the member that has a finite number of elements, a method for the optimization of continuum works with specially arranged material that is difficult to present with the finite geometric characteristics. Distribution of materials is an important factor in this optimization, and various formulations of the problem have been recommended in [4].

\section{THE PROPOSED MANNER OF OPTIMIZATION}

This paper proposes a discrete optimization process using the correction of the axial stiffness of the cross section of simple members (EA) depending on the character and the intensity of stress. Cross sectional area of individual elements, i.e. a simple member of the truss system, is determined by the following expression:

$$
A_{i, j}=\beta_{i} \frac{N_{i, j-1}}{f_{d}}
$$


where $N_{i, j-1}$ is the force in the $\mathrm{i}^{\text {th }}$ simple member from the $\mathrm{j}-1$ iteration, $f_{d}$ is the design strength of reinforcement for tension or of concrete for pressure depending on the character of the axial force in a simple member (pressure or tension) and $\beta_{i}$ is a coefficient that depends on the angle of member inclination in relation to the contours of the analyzed domain. Modulus of elasticity of each element in the truss member depends on the character of the axial force in a simple member (pressure for concrete or tension for steel). The beginning of the analysis implies the formation of networks of linear finite elements with boundary conditions (supports in the nodes of the system) and the external load (concentrated forces in the nodes of the system); hence, the considered domain is modelled. All the nodes of the finite element mesh are connected by simple members. The design is performed iteratively. In the zero iteration all members of the model have the same mechanical and geometrical characteristics of the cross sections. The axial forces in the members are determined on the basis of a such formulated model. Based on the axial forces (compression or tension), the correction of the surface cross-sections is performed according to the expression (4), and for each member the modulus of elasticity is assigned (pressure for concrete or tension for steel). In this manner the model for the next iteration is formed. For each successive iteration, a model obtained by the correction of the axial stiffness of the cross sections of simple member is utilized. The correction is conducted on the character and the intensity of axial forces in the members from the previous iteration. Monitoring the design convergence is done through the value of the determinant of the system stiffness matrix of the connected members with the unknown displacements. The control of the end of the design is defined by the following expression:

$$
\left|D(K s s)_{i}-D(K s s)_{i-1}\right| \leq \varepsilon
$$

where $D\left(K_{s s}\right)_{i}$ and $D\left(K_{s s}\right)_{i-1}$ are the determinants of the system stiffness matrix of the connected members with the unknown displacements in the $\mathrm{i}^{\text {th }}$ and $\mathrm{i}-1$ iteration respectively and $\varepsilon$ is the difference factor, which has a suggested value $10^{-5}$.

For the analysis, the proposed manner of optimization is applied in the computer program (application) that includes a possibility of analysing the plane reinforced concrete members to determine the Strut-and-Tie models for their dimensioning.

During the development of the program, the idea was to try to remove individual members with the lowest stiffness of the system to determine the Strut-and-Tie model, based on recommendations made in [8]. This approach resulted in a possible development of instability of the member occurring at the time when one member is removed. To solve this problem, an attempt was made to search for critical configurations that could occur after each removal of the member, and to replace critical parts of the system with statically equivalent ones, so that further analyses could resume normal.

The solution of previous problems is given by the procedure of stiffness correction of cross-sectional elements on the basis of the characters of axial forces according to the formula (4) but not with their individual removing from the member. The consequence of this approach is the kinematically stable member, though its unstressed parts have a small stiffness, which results in numerical problems in the form of a sudden fall in the value of the stiffness matrix determinant of the connected members system. To solve this problem, the minimum cross-sectional stiffness that an element can have without violating the concept of determining the Strut-and-Tie model is defined. It prevents the "excessive" fall in 
the stiffness of the cross sections of certain parts of the member that, according to the nature of the stress transfer, do not significantly participate in the load transfer.

Based on a number of analyses for the common reinforced concrete members, it has been concluded that the optimum limit of the minimum value of stiffness of the cross-section element is $0.01 \%$ of the value from the first iteration of the analysis (all simple members in the system have the same value of the elastic modulus and the cross-sectional area in the first iteration of the analysis).

The previously described procedure for determining the Strut-and-Tie models according to the expression (4) is applied on a reinforced concrete cantilever wall member with the geometrical and mechanical characteristics shown in Table 1.

Table 1 Cantiliver wall member - geometrical and mechanical characteristics

\begin{tabular}{ll} 
Member & Characteristics \\
\hline L $=3000 \mathrm{~mm}$ \\
$\mathrm{~h}=3000 \mathrm{~mm}$ \\
$\mathrm{~d}=200 \mathrm{~mm}$ \\
$\mathrm{P}=100 \mathrm{kN}$ \\
$\mathrm{E}=31.5 \mathrm{GPa}$ \\
$\mu$
\end{tabular}

The system of simple elements which models the member is shown in Figure 4 a). The initial state analysis assumes that all elements have the same geometric and mechanical characteristics of the cross sections.

a)
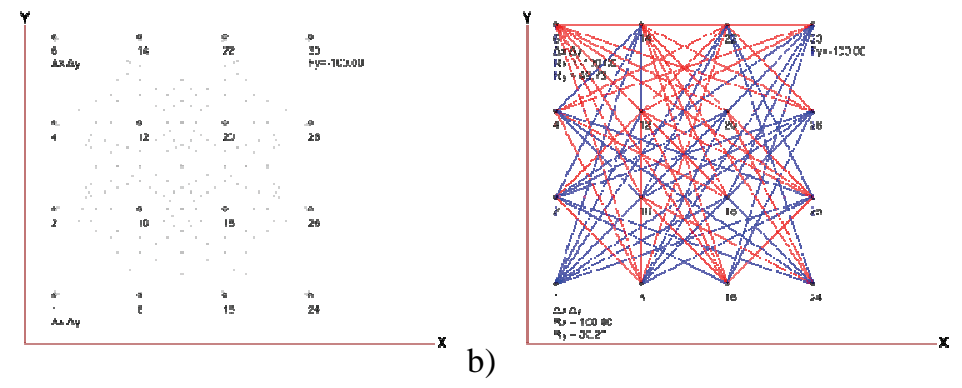

Fig. 4 Cantiliver wall member - a) model , b) axial forces in the first iteration

In the first iteration, the forces in the simple elements on the initial model are determined. Based on the nature of axial forces (tension or pressure), the correction of the cross section surface is performed using the expression (4). Axial forces in the first iteration are shown in Figure 4 b). Compressed elements are marked blue, and tension ones are marked red.

Axial forces in 1, 5, 15 and 26 iterations are shown in Figure 5. Members with the dominant values of axial forces in particular are highlighted with thicker lines. 

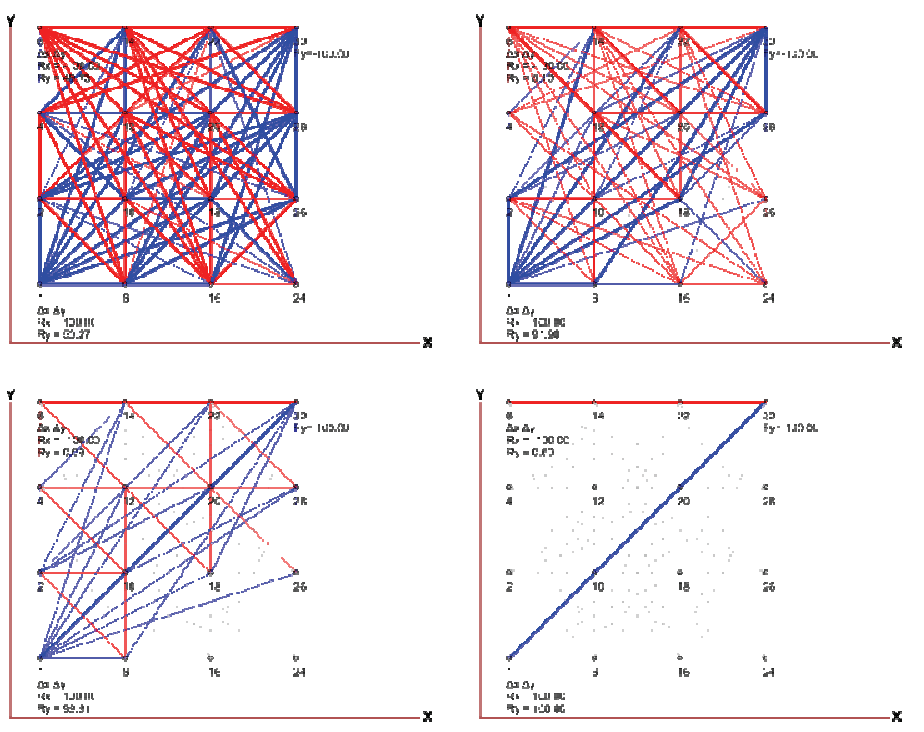

Fig. 5 Cantiliver wall member - axial forces in the members - 1, 5, 15 and 26 iteration

\section{ANALYSIS}

The proposed procedure for the determination of the Strut-and-Tie model is applied on five examples of reinforced concrete members. The analysis of principal stresses for the comparison of the obtained models is carried out using the commercial software for the structural analysis of members in the case of plane stress state.

The first example is the static simple deep beam that is loaded with a concentrated force in the middle of the span. Geometrical and mechanical characteristics of the system are shown in Table 2.

Table 2 Example 1 - deep beam

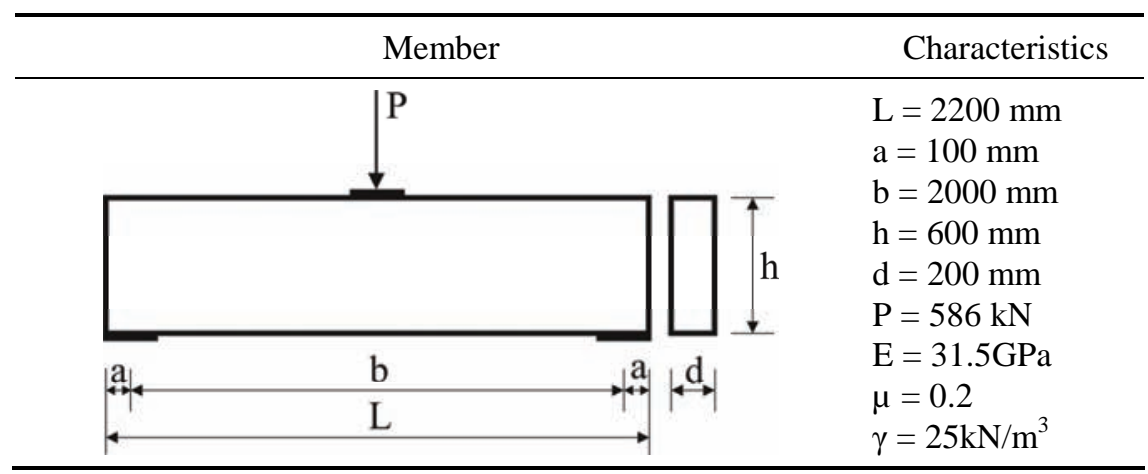


The proposed Strut-and-Tie model [10] and the model given by the computer program are shown in Table 3. Based on the analysis it can be concluded that both models are matching in the form and values of axial forces in the simple elements. According to the trajectories of principal stresses of the deep beam (Figure 6) it can be observed that the obtained model follows the propagation directions of principal stresses.

Table 3 Example 1 - Strut-and-Tie model

Proposal [10] Computer program

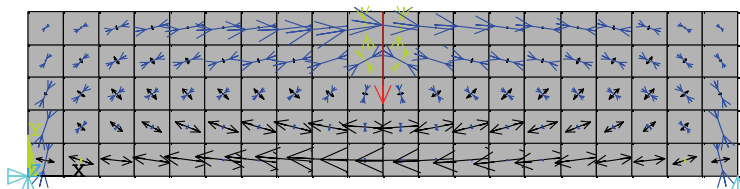

Fig. 6 Example 1 - Trajectories of principal stresses

The second example is a static simple deep beam that is symmetrically loaded with two concentrated forces in the thirds of the span. Geometrical and mechanical characteristics of the system are shown in Table 4. The proposed Strut-and-Tie model [10] and the other model obtained by the computer program are shown in Table 5. They are matching in the form and values of axial forces. Likewise, the obtained model follows the propagation directions of principal stresses, Figure 7.

Table 4 Example 2 - deep beam

\begin{tabular}{lll}
\hline & Member & Characteristics \\
\hline & &
\end{tabular}


Table 5 Example 2 - Strut-and-Tie model

Proposal [10] Computer program

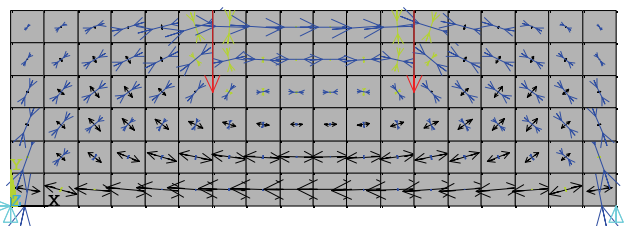

Fig. 7 Example 2 - Trajectories of principal stresses

The third example is a static simple deep beam that is asymmetrically loaded with a concentrated force. Geometrical and mechanical characteristics of the system are shown in Table 8.

Table 8 Example 3 - deep beam

Member

The proposed Strut-and-Tie model [11] and the model obtained by the computer program are shown in Table 9. Results of the analysis in terms of axial forces are shown in Table 10. 
Table 9 Example 3 - Strut-and-Tie model

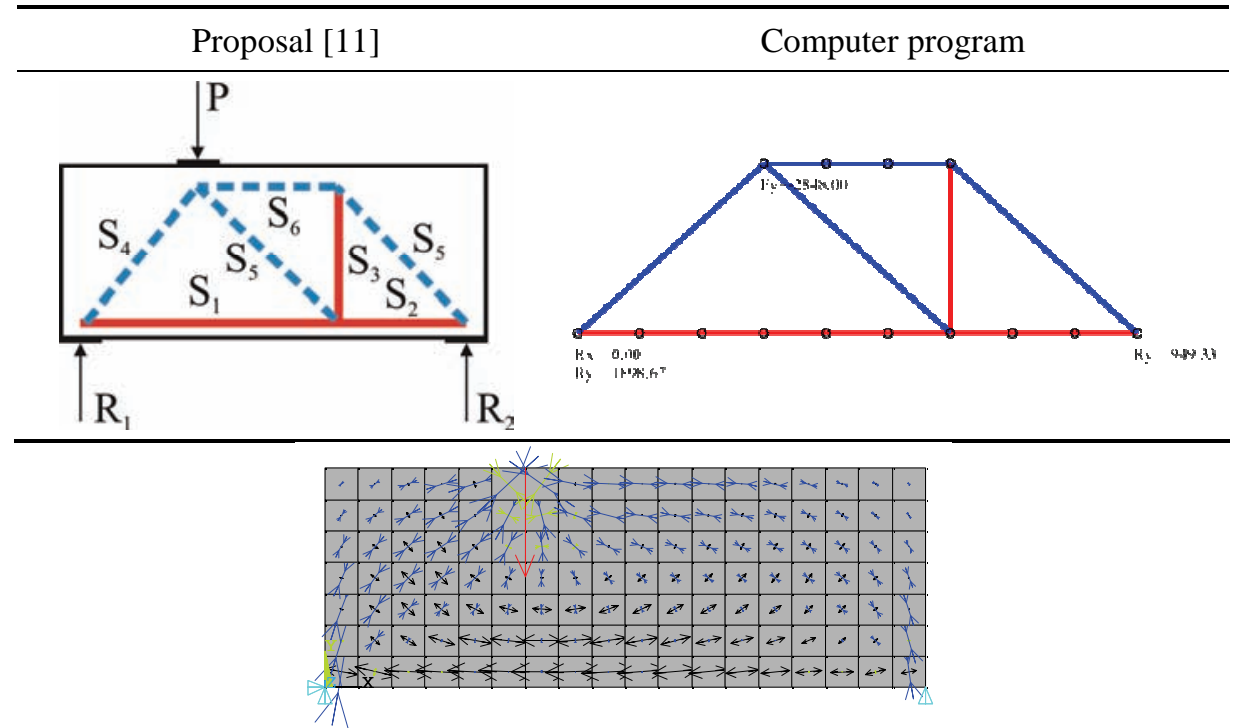

Fig. 8 Example 3 - Trajectories of principal stresses

Based on the shown results, one can conclude that the Strut-and-Tie model obtained by the computer program and the proposed one [11] are matching in form, Table 9. Axial forces in the members of the two models differ by no more than approximately $7 \%$, Table 10. As shown in Figure 8, the Strut-and Tie model obtained by the computer program follows the trajectories of principal stresses.

Table 10 Example 3 - Axial forces in the members of the Strut-and-Tie models

\begin{tabular}{rrrrcr}
\hline \multicolumn{5}{c}{$\mathrm{S}[\mathrm{kN}]$} \\
\hline$/$ & Proposal [11] & Program & $/$ & Proposal [11] & Program \\
\hline $\mathrm{S}_{1}$ & +1931 & +2067 & $\mathrm{~S}_{5}$ & -1353 & -1403 \\
$\mathrm{~S}_{2}$ & +966 & +1033 & $\mathrm{~S}_{6}$ & -966 & -1033 \\
$\mathrm{~S}_{3}$ & +943 & +949 & $\mathrm{R}_{1}$ & 1904 & 1899 \\
$\mathrm{~S}_{4}$ & -2710 & -2806 & $\mathrm{R}_{2}$ & 943 & 949 \\
\hline
\end{tabular}

Two examples of complex wall members with holes are shown in Tables 11 and 12 and their proposals in the literature [10] and [3]. 
Table 11 Example 4 - Strut and Tie model of wall member

Proposal [10] Computer program

Table 12 Example 5 - Strut and Tie model of wall member

Proposal [3] Computer program

Based on the result shown in Tables 11 and 12, it can be concluded that the Strut-andTie models obtained using the computer program and the proposed models [10] and [3] are matching in form. Obtaining unequivocal forms of the Strut-and-Tie model in some cases, especially complex, is not always possible to achieve, since the density of nodes network affects the manner to obtain them. Thus, an engineer utilizing the program must determine the final model on the basis of their experience, which indicates that the proposed concept implemented in the computer program also has certain drawbacks.

\section{CONCLUSION}

Faster and simpler analysis of the behaviour of loaded reinforced concrete members is possible using the Strut-and-Tie method that reduces the member into a truss system. Discrete topological optimization lies in the basis of the Strut-and-Tie method, whose application can provide a real insight into the stress-strain state of reinforced concrete elements.

The computer program presented in this paper applies discrete truss systems without removing certain elements. The formation of the Strut-and-Tie models is iterative, by changing the stiffness of cross-sectional members according to the expression (4). In this manner, one can overcome the problem of preserving stability of the system which may occur when certain elements are removed. The computer program offers the possibility of determining the 
Strut-and-Tie models of reinforced concrete members in the plane and the design of their stressstrain state. Results of the described concept application and the developed software have shown the possibility of practical application of the member of simple and complex geometry, with or without openings. Though present, the problem of numerical stability calculation is solvable in an automatic form, and the need for interventions of the experiential nature is significantly diminished and reduced to the choice of density of used finite element meshes.

Based on the shown analyses, including a comparison between the obtained truss models from the computer program and the existing models as already recommended in the literature, as well as a confirmation of plane stress state of commercial software for structural analysis of structures, it can be concluded that the proposed method for determining the Start-and-Tie model can be applied for the analysis of reinforced concrete members in the plane.

\section{REFERENCES}

1. ACI Code 318-02 - Building Code Requirements for Structural Concrete and Commentary \& PCA Notes on 318-02, 2002.

2. American Association of State Highway and Transpotation Officials (AASHTO), Highway Subcommittee on Bridge and Structures: Verification and Implementation of Strut-and-Tie Model in LRFD Bridge Design Specifications, November 2007.

3. Bruggi M. Generating strut-and-tie patterns for reinforced concrete structures using topology optimization, Computers and Structures 87 (2009), pp 1483-1495.

4. Burns S.A. Recent Advances in Optimal Structural Design, The Structural Engineering Institute of the American Society of Civil Engineers, May 3, 2002.

5. CEB-FIP - (fib), Praktično projektovanje sa konstrukcionim betonom, Sarajevo, februar 2002.

6. EN 1992-1-1;2004, Evrokod 2, Proračun Betonskih Konstrukcija, Deo 1-1: Opšta Pravila i Pravila za zgrade, Beograd, februar 2006.

7. Moen C. D., Guest J. K.: Reinforced concrete analysis and design with truss topology optimization, $3^{\text {rd }}$ fib International Congress 2010.

8. Kostić N. Computer-based development of stress fields, $6^{\text {th }}$ International $\mathrm{PhD}$ Symposium in Civil Engineering, Zurich, August 23-26, 2006.

9. Kostić N. Topologie des champs de contraintes pour le dimensionnement des structures en beton arme, These $\mathrm{N}^{\mathrm{0}} 4414$ (2009), Ecole Polytechnique federale de Lausanne, Suisse, 11 Juin 2009.

10. Reineck K.H.: Examples for the Design of Structural Concrete with Strut-and-Tie Models, American Concrete Institute, 2002.

11. Wight J. K., Parra-Montesinos G. J.: Strut-and-Tie Model for Deep Beam Design, May 2003.

\section{AUTOMATSKO GENERISANJE ARMIRANOBETONSKIH RAVANSKIH STRUT-AND-TIE MODELA \\ Anka Starčev-Ćurčin, Andrija Rašeta, Zoran Brujić}

U ovom radu dat je predlog za određivanje Strut-and-Tie modela armiranobetonskih elemenata $u$ ravni. Za potrebe analiza razvijen je program "ST metod", a primenjena je diskretna topološka optimizacija koja koristi rešetkasti nosač za proračun naponsko-deformacijskog stanja stvarnog nosača. Metoda može da se koristi za analizu dela ili celog nosača, a posebno je pogodna za primenu na mestima nagle promene statičkih veličina i/ili geometrijskih karakteristika nosača. Generalni princip metode je da se pritisnutim štapovima zamenjuju betonski delovi (površine ili zapremine) armiranobetonskog elementa, a da se zategnutim štapovima zamenjuje armatura.

Ključne reči: MKE, optimizacija, Strut-and-Tie metod, rešetkasti nosač 